
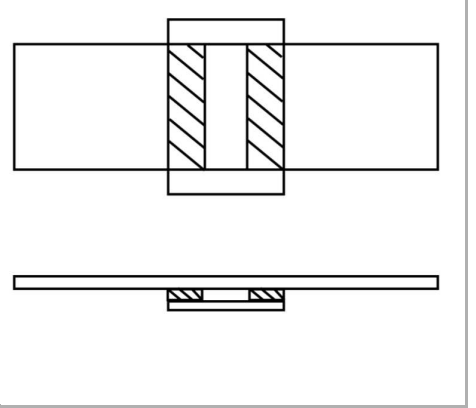

MAR 02, 2021

\section{open ठAccess}

\section{DOI:}

dx.doi.org/10.17504/protocol s.io.bcjdiui6

\section{External link:}

https://www.pnas.org/content /114/38/E7969

Protocol Citation: Uriel Barboza Perez, Ekaterina Krasnopeeva, Jerko Rosko, Teuta Pilizota 2021. Tunnel Slide Preparation for Motor Speed Recordings . protocols.io

https://dx.doi.org/10.17504/p rotocols.io.bcjdiui6

\section{MANUSCRIPT CITATION:}

Osmotaxis through changes in motor speed. Jerko Rosko, Vincent A. Martinez, Wilson C. K. Poon, Teuta Pilizota Proceedings of the National Academy of Sciences Sep 2017, 114 (38) E7969-E7976; DOI:

10.1073/pnas.1620945114

License: This is an open access protocol distributed under the terms of the Creative Commons Attribution License, which permits unrestricted use, distribution, and reproduction in any medium, provided the original author and source are credited

\title{
(3) Tunnel Slide Preparation for Motor Speed Recordings
}

Uriel Barboza

Perez ${ }^{1}$,

Teuta

Pilizota ${ }^{1}$

${ }^{1}$ University of Edinburgh

Ekaterina Krasnopeeva: Currently at IST Austria

Jerko Rosko: Currently at Laboratoire Jean Perrin, Paris

\section{Uriel Barboza Perez}

University of Edinburgh

\section{ABSTRACT}

Preparation of our standard tunnel-slide, used for BFM speed measurements and experiments involving rapid media exchange.

\section{MATERIALS}

\section{MATERIALS}

88

Microscope Slides Fisher Scientific Catalog

\#12332098

Coverslip 22x40mm \#1 Fisher Scientific Catalog

$\# 12332118$

Scotch Double Sided Tape Scotch $®$ Brand Catalog

\#7100107082

\section{SAFETY WARNINGS}

(1) Coverslips are really sensitive and could break when assembling the tunnel slide. For your safety wear adequate eye protection.

\section{BEFORE START INSTRUCTIONS}

Make sure coverslips and microscope slides are sterile and dust-free 
Protocol status: Working

We use this protocol and it's

working

Created: Feb 13, 2020

Last Modified: Mar 02,

2021

PROTOCOL integer ID:

33093

\section{Tunnel Slide Making}

1

Take out 22x40 mm coverslips and standard microscope slides.

2

Cut 2 pieces of Scotch sticky tape and tape them perpendicularly on the microscope slide.

Note

The separation between the tapes should be approximately $3-4 \mathrm{~mm}$ apart from each other. 


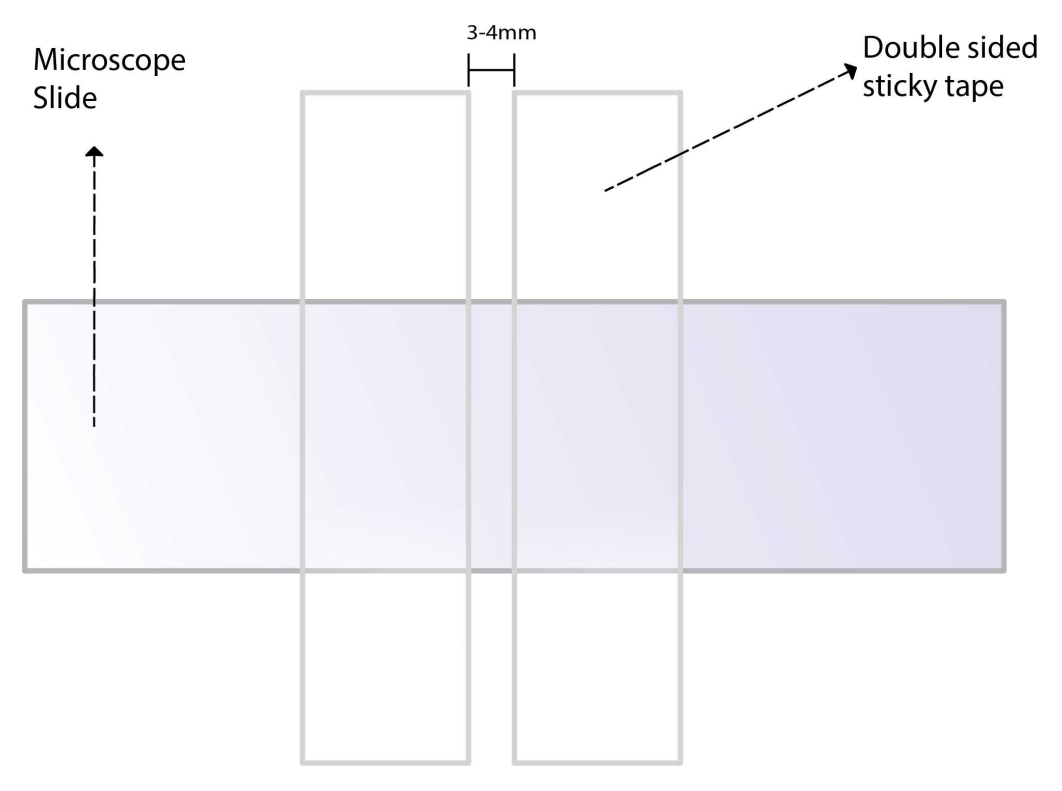

3

Cut the excess tape off with a razor and place the coverslip onto the slide gently.

Use pipette tips to push it down gently and to remove air.

Cover Slip

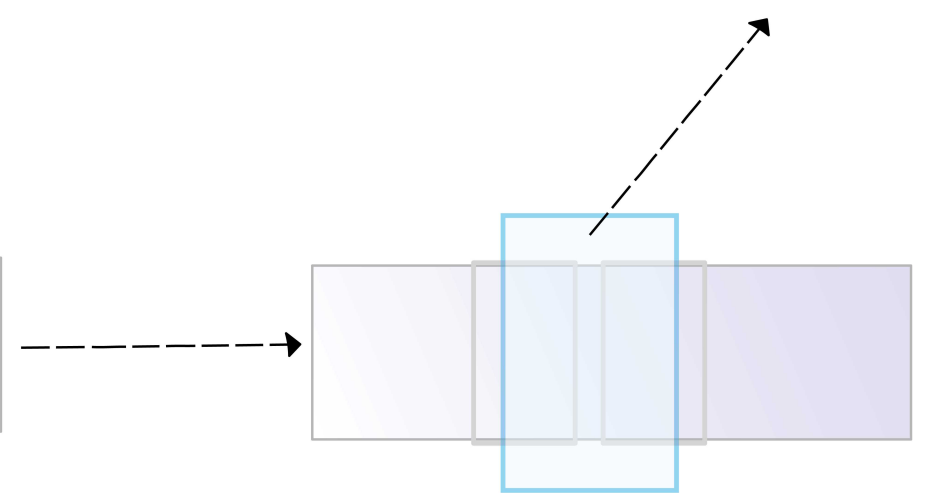

4 Once finished, flip the tunnel slide so that you have the coverslip at the bottom and the tunnel entries are accessible .

Note: The channel that was made on the slide has a capacity of 8-10 uL. 
